\title{
Do we need different predictive equations for the acute and late phases of critical illness? A prospective observational study with repeated indirect calorimetry measurements
}

\author{
Pei Chien Tah (D ${ }^{1,2}$, Bee Koon Poh $\mathbb{D D}^{3}$, Chee Cheong Kee $\mathbb{D}^{4}{ }^{4}$, Zheng-Yii Lee ${ }^{1}{ }^{1}$, Vineya-Rai Hakumat-Rai ${ }^{5}$, Mohd Basri Mat Nor ${ }^{6}$, \\ Mazuin Kamarul Zaman ${ }^{7}$, Hazreen Abdul Majid (D) ${ }^{8,9}$ and M. Shahnaz Hasan (iD) ${ }^{1 凶}$
}

๑ The Author(s), under exclusive licence to Springer Nature Limited 2021, corrected publication 2021

\begin{abstract}
BACKGROUND: Predictive equations (PEs) for estimating resting energy expenditure (REE) that have been developed from acute phase data may not be applicable in the late phase and vice versa. This study aimed to assess whether separate PEs are needed for acute and late phases of critical illness and to develop and validate PE(s) based on the results of this assessment.

METHODS: Using indirect calorimetry, REE was measured at acute ( $\leq 5$ days; $n=294$ ) and late ( $\geq 6$ days; $n=180$ ) phases of intensive care unit admission. PEs were developed by multiple linear regression. A multi-fold cross-validation approach was used to validate the PEs. The best PEs were selected based on the highest coefficient of determination $\left(R^{2}\right)$, the lowest root mean square error (RMSE) and the lowest standard error of estimate (SEE). Two PEs developed from paired 168-patient data were compared with measured REE using mean absolute percentage difference.

RESULTS: Mean absolute percentage difference between predicted and measured REE was $<20 \%$, which is not clinically significant. Thus, a single PE was developed and validated from data of the larger sample size measured in the acute phase. The best PE for REE (kcal/day) was 891.6(Height) + 9.0(Weight) +39.7 (Minute Ventilation) -5.6 (Age) -354 , with $R^{2}=0.442, \mathrm{RMSE}=348.3, \mathrm{SEE}=325.6$ and mean absolute percentage difference with measured REE was: $15.1 \pm 14.2 \%$ [acute], $15.0 \pm 13.1 \%$ [late].

CONCLUSIONS: Separate PEs for acute and late phases may not be necessary. Thus, we have developed and validated a PE from acute phase data and demonstrated that it can provide optimal estimates of REE for patients in both acute and late phases.

TRIAL REGISTRATION: ClinicalTrials.gov NCT03319329.
\end{abstract}

European Journal of Clinical Nutrition (2022) 76:527-534; https://doi.org/10.1038/s41430-021-00999-y

\section{BACKGROUND}

Indirect calorimetry $(\mathrm{IC})$ is the reference standard for measuring the energy expenditure of critically ill patients in the intensive care unit (ICU) [1, 2]. Optimizing energy provision with daily IC measurements in the ICU may confer clinical benefits [3-5]. However, IC is not commonly used [6]. This is due to the high cost, poor insurance reimbursement, and lack of trained personnel to operate the equipment and to interpret the results [7, 8]. Hence, clinicians need to rely on predictive equation (PE) for estimating patients' energy expenditure.

In the ICU, resting energy expenditure (REE) is calculated using PEs with variables such as weight, height, age, sex, body temperature and minute ventilation [9]. PEs developed in healthy populations, such as the Harris-Benedict [10] and Mifflin-St. Jeor equations [11], are widely used in the ICU setting. While PEs developed in the critically ill population, such as the Penn State [9], Swinamer [12], and Faisy [13] equations, were developed from Caucasians and data of patients in the acute phase ( $\leq 5$ days). Our recent study found that none of the commonly used PEs could optimally estimate measured REEs of patients in different phases of critical illness [14]. Furthermore, we found that REE during the acute phase of critical illness is generally lower than the late phase (6-10 days), while REE in the chronic phase ( $\geq 11$ days) was not significantly different from the late phase [14]. Based on these results, we hypothesized that the use of separate PE for the acute ( $\leq 5$ days) and later phases ( $\geq 6$ days; collectively known as the late

\footnotetext{
${ }^{1}$ Department of Anaesthesiology, Faculty of Medicine, University of Malaya, Kuala Lumpur, Malaysia. ${ }^{2}$ Department of Dietetics, University of Malaya Medical Centre, Kuala Lumpur, Malaysia. ${ }^{3}$ Nutritional Sciences Programme \& Centre for Community Health Studies (ReaCH), Faculty of Health Sciences, Universiti Kebangsaan Malaysia, Kuala Lumpur, Malaysia. ${ }^{4}$ Sector for Biostatistics \& Data Repository, National Institutes of Health (NIH), Ministry of Health, Selangor, Malaysia. ${ }^{5}$ Department of Anaesthesiology, KPJ Tawakkal Specialist Hospital, Kuala Lumpur, Malaysia. ${ }^{6}$ Department of Anaesthesiology, Kulliyyah of Medicine, International Islamic University Malaysia, Kuala Lumpur, Malaysia. ${ }^{7}$ Centre of Dietetics Studies, Faculty of Health Sciences, Universiti Teknologi MARA, Selangor, Malaysia. ${ }^{8}$ Centre for Population Health, Department of Social and Preventive Medicine, Faculty of Medicine, University of Malaya, Kuala Lumpur, Malaysia. ${ }^{9}$ Department of Nutrition, Faculty of Public Health, Universitas Airlangga, Surabaya, Indonesia. 两email: shahnaz@ummc.edu.my Edited by Professor Claudio Maffeis
}

Received: 17 February 2021 Revised: 31 July 2021 Accepted: 11 August 2021 Published online: 30 August 2021 
phase) would further optimize the nutrition care of critically ill patients, especially in the setting where IC is not available. However, the PermiT trial [15] found a difference of $~ 25 \%$ of the calculated caloric requirement did not result in any differences in clinical outcomes. Therefore, this study has two objectives: (a) to assess whether separate PEs for acute and late phases are needed, (b) to recommend the best $\mathrm{PE}(\mathrm{s})$ for our population based on the result of the first objective. A priori, we set a mean absolute percentage difference threshold of $\geq 20 \%$ between the predicted REE calculated from the developed PEs with the measured REE at acute and late phases. If the predicted REE calculated by the acute $\mathrm{PE}$ and measured REE in the late phase has an absolute mean difference of $\geq 20 \%$ or vice versa, then two PEs at different phases may be needed. Otherwise, a single PE will be sufficient.

\section{METHODS \\ Study design and subjects}

A prospective observational study was conducted from December 2016 to November 2018 in a mixed medical-surgical ICU at the University of Malaya Medical Centre (UMMC), Malaysia. The study protocol was approved by the Medical Research Ethics Committee (MREC), UMMC (MREC ID NO: 20161024-4407) and registered with the National Medical Research Register (NMRR) Malaysia (NMRR.ID: NMRR-16-2030-33143) and ClinicalTrials.gov (NCT03319329). Informed consent was obtained from the patients or their legal representative. The inclusion and exclusion criteria are the same as our previous study [14]. In this study, we further excluded patients with extreme body mass index (BMI), $<15 \mathrm{~kg} / \mathrm{m}^{2}$ or $>40 \mathrm{~kg} / \mathrm{m}^{2}$, as their metabolic requirement might be very different from that of other patients [16].

\section{Sample size estimation}

The sample size for the development of new PEs was estimated based on the assumptions that minimum squared multiple correlation coefficients of $0.15,[13]$ and PEs have at least three predictor variables with a significance level (a) at 0.05 , and power of the study at $80 \%$ [17]. The calculated sample size was 220 patients. However, with an estimated non-response or drop-out rate of $30 \%$, the sample size required was 315 patients.

Besides, the sample size for comparison of mean absolute percentage difference and validation of newly developed PEs was estimated based on the assumption that the intra-class correlation coefficient (ICC) between predicted and measured REE was expected to be about 0.9. We further assumed that the lower limit of expected ICC would be 0.8, two measurements of REE would be conducted on each patient, together with a significance level (a) at 0.05 , and power of the study at $80 \%$, the minimum sample size was 134 patients [18]. With an estimated nonresponse or drop-out rate of $20 \%$, the sample size required for paired comparison and validation was 168 patients.

\section{Measurements and instrumentation}

REE was measured using COSMED Quark RMR 2.0 (COSMED srl, Rome, Italy). The standard protocol for conducting the measurement was followed $[7,19]$. Most of the IC measurements were performed in the morning (between 08:00 and 12:00). The REE was recorded after a 30 min non-fasting steady state, in accordance with standard protocol and manufacturer instructions. Respiratory variables [oxygen consumption $\left(\mathrm{VO}_{2}\right)$, carbon dioxide production $\left(\mathrm{VCO}_{2}\right)$, respiratory quotient $\left.(\mathrm{RQ})\right]$ were collected during the IC measurements. IC measurement was conducted in the acute phase ( $\leq 5$ days), and in the late phase ( $\geq 6$ days) if the patient was still mechanically ventilated in the ICU, up to 14 days.

\section{Patient data}

The list of data collected is in the Supplementary Appendix. All data were recorded in a standardized case report form.

\section{Statistical analysis for model development and validation}

All statistical analysis was performed using SPSS for Windows (version 24.0, SPSS Inc., Chicago, II, USA). Statistical significance was defined as two-tailed $p<0.05$. Descriptive statistics were used to describe demographic, nutritional, respiratory, and clinical characteristics.
The multi-fold cross-validation approach was employed to develop and validate the PEs among the patients who have a measured REE in both the acute and later phases $(n=168)[20,21]$. The fivefold cross-validation approach was used to develop and validate PE for both phases, whereby subjects were randomly divided into five groups. PEs were then generated five times for each phase, each time with four groups as the validation group (training folds) and the one remaining group as the cross-validation group (test fold).

Simple linear regression (SLR) analysis was applied to identify the demographic, nutritional, respiratory, and clinical characteristics variables that were significantly associated with measured REE. These variables were then entered into multiple linear regression (MLR) analysis. The stepwise selection of variables was applied in MLR analysis to generate the PE. To develop the best PE, the variable which had contributed to the model with changes in the coefficient of determination $\left(R^{2}\right)$ of $<0.05$ was removed from the MLR model. The final model was checked for interactions and multicollinearity among the independent variables. The final model was then cross-validated with the cross-validation group. The PEs with the highest $R^{2}$, the lowest root mean square error (RMSE) and the lowest standard error of estimate (SEE), for acute and late phases, were identified as the best PEs. $R^{2}$ was prioritised as the SE or RMSE can be reduced or minimised with a large sample while $R^{2}$ is not affected by sample size. In addition to these statistical considerations, other factors considered when selecting the independent variables to be used in the PE were: (i) the variable should be practical and correspond with the physiological concept, (ii) the final PE should be simple to apply in the ICU settings, and (iii) the variable should contribute towards the accuracy of predicting the REE.

The predicted REE calculated from the developed PEs were then compared with measured REE during the acute and late phases by looking at the mean absolute percentage difference. Overestimation or underestimation was defined as a percentage difference of $>10 \%$ or $>-10 \%$ $[22,23]$, respectively, between the predicted and the measured REE.

We found that the mean absolute percentage difference was $<20 \%$ between the calculated REE for the acute phase with REE measured during the acute and late phases. Similarly, the calculated REE for the late phases and REE measured during the acute and late phases also had mean absolute percentage difference of $<20 \%$. Hence, we decided to develop only one PE with a larger sample of patients from the acute phase $(n=294)$. Tenfold cross-validation was used because a higher number of folds leads to a less biased predictive model for larger sample sizes. The best PE were selected based on the aforementioned method.

\section{RESULTS}

During the study period, a total of 2504 patients were admitted to the ICU. After screening for eligibility, 315 patients were recruited. Twenty-one patients were excluded from the study due to missing data $(n=6)$, technical issues $(n=4), \mathrm{BMl}<15 \mathrm{~kg} / \mathrm{m}^{2}(n=3)$ and $\mathrm{BMI}>40 \mathrm{~kg} / \mathrm{m}^{2}(n=8)$. A total of 294 (acute phase) and 180 (late phase) patients were included in the final analysis (Fig. 1). Demographic and nutritional characteristics of eligible patients at two different phases of critical illness are presented in Table 1. There were 168 patients who had REE measured in both the acute and late phases. Mean REE was significantly lower in the acute $(1747 \pm 429 \mathrm{kcal})$ compared to the late phase $(1865 \pm 462 \mathrm{kcal})(p$ $<0.001)$. Data on respiratory support and clinical variables recorded during IC measurements are summarized in Table S1.

In the SLR analysis among 168 patients, the association between measured REE and 15 quantitative variables in the acute phase were statistically significant (Table S2). Among the 15 quantitative variables, variables with the highest correlation coefficients $(r)$ with REE were height $(r=0.524, p<0.001)$, weight $(r=0.477, p<0.001)$, sex $(r=-0.398, p<0.001)$ and minute ventilation (Ve) $(r=0.394, p<0.001)$. In the late phase, we found statistically significant relationships between measured REE and 15 quantitative variables. Among the 15 quantitative variables, variables with the highest correlation coefficients with REE were weight $(r=0.512, p<0.001)$, height $(r=0.498, p<0.001)$, energy intake in the previous $24 \mathrm{~h}(r=0.496, p<0.001)$, and maximum minute ventilation in the previous $24 \mathrm{~h}$ (VeMax) $(r=0.418, p<$ 


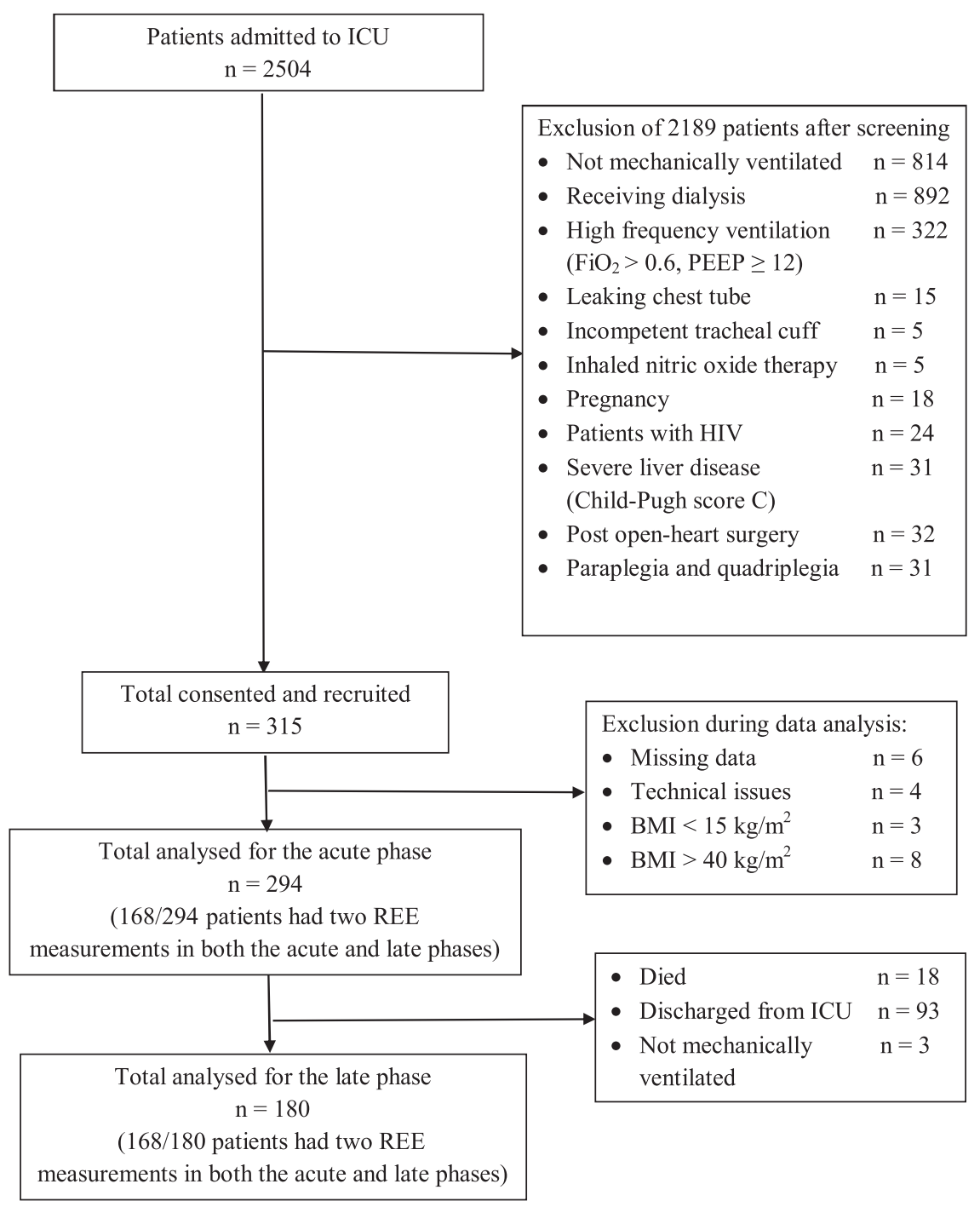

Fig. 1 Exclusion flow diagram. BMI body mass index, $\mathrm{FiO}_{2}$ inspired oxygen, HIV human immunodeficiency virus, IC indirect calorimetry, ICU intensive care unit, PEEP positive end-expiratory pressure, REE resting energy expenditure.

0.001). For the 294 patients in the acute phase, we found statistically significant associations between measured REE and 18 quantitative variables (Table S3). Among the 18 quantitative variables, variables with the highest correlation coefficients $(r)$ with REE were height $(r=0.515, p<0.001)$, weight $(r=0.487, p<$ $0.001)$, sex $(r=0.425, p<0.001)$ and $\operatorname{Ve}(r=0.412, p<0.001)$.

In the acute phase among 168 patients with REE measurement in both phases, MLR analysis and fivefold cross-validation were performed and the developed PEs are reported in Table 2A. The best PE for estimating REE (kcal/day) was 1627.8 (Height in $\mathrm{m}$ ) +25.3 (Maximum minute ventilation $24 \mathrm{~h}$ ) +8.4 (Weight in $\mathrm{kg}$ ) -1830.3 , with $\mathrm{R}^{2}=0.414$, RMSE $=294.0$, SEE $=$ 343.7. $R^{2}$ for equations $2 a$ and $3 a$ are almost similar but equation $2 a$ has a much lower RMSE; hence, equation $2 a$ was selected. In the late phase, MLR analysis and fivefold crossvalidation were performed and the developed PEs are shown in Table 2B. The best PE for REE was $1008.3+14.4$ (Weight in $\mathrm{kg}$ ) + 26.1 (Maximum minute ventilation $24 \mathrm{~h}$ ) - 7.9 (Age), with $R^{2}=0.498, \mathrm{RMSE}=423.6, \mathrm{SEE}=335.9$. These PEs are known as $\mathrm{PE}$ (acute) and PE(late).

Comparison of PEs developed among the 168 patients for the acute and late phases with measured REE during the acute and late phases is shown in Table 3. When comparing with measured
REE during the acute phase, $\mathrm{PE}$ (acute) and $\mathrm{PE}$ (late) had mean absolute percentage differences of $15.2 \pm 13.8 \%$ and $18.6 \pm 17.7 \%$, respectively. $\mathrm{PE}$ (acute) underestimated $25.6 \%$ and overestimated $30.4 \%$, while $\mathrm{PE}$ (late) underestimated $15.5 \%$ and overestimated $45.8 \%$ of the subjects' measured REE. When compare with measured REE during the late phase, $\mathrm{PE}$ (acute) and $\mathrm{PE}$ (late) had a mean absolute percentage difference of $15.7 \pm 12.1 \%$ and $14.7 \pm$ $14.7 \%$, respectively. $\mathrm{PE}$ (acute) underestimated $39.9 \%$ and overestimated $22.6 \%$, while $\mathrm{PE}$ (late) underestimated $18.5 \%$ and overestimated $32.7 \%$ of the subjects' measured REE. As the mean absolute percentage difference threshold of $\geq 20 \%$ between the predicted energy requirement from the developed PEs with the measured REE at acute and late phases did not exceed the threshold of $20 \%$ determined a priori, we developed a single PE among all patients with REE measured in the acute phase, as it has a larger sample size $(n=294)$ and hence better statistical precision.

Among the 294 patients, MLR analysis and ten-fold crossvalidation was performed and the developed PEs are reported in Table 4. The best PE for estimating REE (kcal/day) was 891.6 (Height in $\mathrm{m}$ ) +9.0 (Weight in $\mathrm{kg}$ ) +39.7 (Minute Ventilation)-5.6 (Age)-354, with $R^{2}=0.442$, RMSE $=348.3, \mathrm{SEE}=325.6$. This PE is known as PE(all). A comparison of measured with predicted REE 
Table 1. Demographic, nutritional, and descriptive characteristics.

\begin{tabular}{|c|c|c|c|c|}
\hline \multirow[t]{2}{*}{ Variable } & \multirow[t]{2}{*}{ All patients $(n=294)$} & \multicolumn{3}{|c|}{ Patients with measured REE for 2 phases } \\
\hline & & Acute $(n=168)$ & Late $(n=168)$ & $p$ value \\
\hline Age, years & $54.3 \pm 18.6$ & $54.1 \pm 19.0$ & & - \\
\hline Male & $192(65.3 \%)$ & $111(61.7 \%)$ & & \\
\hline Female & $102(34.7 \%)$ & $69(38.3 \%)$ & & \\
\hline Race & & & - & \\
\hline Chinese & $108(36.7 \%)$ & $70(38.9 \%)$ & & \\
\hline Indian & $77(26.2 \%)$ & $42(23.3 \%)$ & & \\
\hline Others & $19(6.5 \%)$ & $12(6.7 \%)$ & & \\
\hline Admission category & & & & - \\
\hline Medical & $159(54.1 \%)$ & $101(56.1 \%)$ & & \\
\hline Height, m & $1.7 \pm 0.1$ & $1.7 \pm 0.1$ & $1.7 \pm 0.1$ & $0.319^{a}$ \\
\hline Body mass index (BMI), $\mathrm{kg} / \mathrm{m}^{2}$ & $25.1 \pm 5.0$ & $25.2 \pm 5.2$ & $25.0 \pm 5.1$ & $0.034^{a}$ \\
\hline Measured REE, kcal & $1757 \pm 431$ & $1747 \pm 429$ & $1865 \pm 462$ & $<0.001^{\mathrm{a}}$ \\
\hline Route of nutrition $(n=291)$ & & & & $0.178^{\mathrm{b}}$ \\
\hline Enteral nutrition & $231(79.4 \%)$ & $136(81.0 \%)$ & $140(83.3 \%)$ & \\
\hline Parenteral nutrition & $37(12.7 \%)$ & $19(11.3 \%)$ & $13(7.7 \%)$ & \\
\hline Enteral + Parenteral nutrition & $23(7.9 \%)$ & $13(7.7 \%)$ & $15(8.9 \%)$ & \\
\hline Energy intake previous $24 \mathrm{~h}, \mathrm{kcal} /$ day & $1240 \pm 586$ & $1317 \pm 518$ & $1733 \pm 457$ & $<0.001^{\mathrm{a}}$ \\
\hline Protein intake previous $24 \mathrm{~h}, \mathrm{~g} /$ day & $50.9 \pm 28.2$ & $54.4 \pm 24.2$ & $79.3 \pm 26.4$ & $<0.001^{\mathrm{a}}$ \\
\hline Body cell mass (BCM), kg & $12.8 \pm 3.2$ & $12.7 \pm 3.2$ & $12.4 \pm 3.2$ & $0.006^{\mathrm{a}}$ \\
\hline Vasopressor & $141(48.0 \%)$ & $87(51.8 \%)$ & $47(28.0 \%)$ & $<0.001^{\mathrm{b}}$ \\
\hline Sedation & $160(54.4 \%)$ & $96(57.1 \%)$ & $81(48.2 \%)$ & $0.059^{b}$ \\
\hline Muscle relaxant & $36(12.2 \%)$ & 20 (11.9\%) & $20(11.9 \%)$ & $0.804^{b}$ \\
\hline
\end{tabular}

Acute phase, $\leq 5$ days; APACHE II acute physiology and chronic health evaluation II score, ICU intensive care unit; late phase, $\geq 6$ days, $m$-NUTRIC modified nutrition risk in critically ill score, REE resting energy expenditure, SAPS II simplified acute physiology score II, SOFA sequential organ failure assessment score. Continuous variables are presented as Mean \pm SD or Median (Q1-Q3).

Categorical variables are presented as number of subjects, $n(\%)$.

Significant difference, $p<0.05$;

a paired $t$-test was performed to compare continuous paired data.

${ }^{\mathrm{b}} \mathrm{McNemar}$ test was performed to compare categorical paired data.

'Wilcoxon signed-ranked test was performed to compare non-parametric continuous paired data.

calculated from the PE(all) during the acute and late phases is shown in Table 5 . The mean absolute percentage difference between the measured and predicted REE in the acute and late phases are $15.1 \pm 14.2 \%$ and $15.0 \pm 13.1 \%$, respectively. In the acute phase, the calculations by $\mathrm{PE}$ (all) underestimated $23.5 \%$ and overestimated $32.0 \%$ of subjects' measured REE, with a mean percentage difference against the measured REE of $-12.1 \pm 8.4 \%$ and $17.6 \pm 17.1 \%$, respectively. In the late phase, a total of $33.3 \%$ and $22.2 \%$ of the subject's measured REE was underestimated and overestimated by $\mathrm{PE}($ all), respectively, with a mean percentage difference against the measured REE of $-13.5 \pm 8.6 \%$ and $17.0 \pm$
17.2\%, respectively. A simple Microsoft Excel Tah et al. equation calculator (Supplementary File) was developed as an aid for ease of application.

\section{DISCUSSION}

To the best of our knowledge, this is the first prospective study demonstrated that two separate predictive equations is not necessary for acute ( $\leq 5$ days) and late ( $\geq 6$ days) phases of critical illness. Hence, we have developed and internally validated a single $\mathrm{PE}$ and demonstrated that it is useful for estimating the REE of 
Table 2. Fivefold cross-validation for predictive equations developed from same patients in the acute phase $(n=168)$ and late phase $(n=168)$.

A

Acute phase $(<5$ days $)$

\begin{tabular}{|lllll} 
Test set & Developed predictive equations & $\boldsymbol{R}^{2}$ & RMSE & SEE \\
\hline $\mathbf{1}$ & $\mathrm{REE}=1686.9 \mathrm{Ht}+30.7 \mathrm{VeMax}+8.0 \mathrm{Wt}-1975.8$ & 0.401 & 344.6 \\
\hline $\mathbf{2}$ & $\mathrm{REE}=1627.8 \mathrm{Ht}+25.3 \mathrm{VeMax}+8.4 \mathrm{Wt}-1830.3^{\mathrm{a}}$ & 0.414 & 294.0 & 343.7 \\
\hline $\mathbf{3}$ & $\mathrm{REE}=2048.8 \mathrm{Ht}+115.7 \mathrm{TMax}+7.1 \mathrm{Wt}-6462.8$ & 0.442 & 408.6 & 318.8 \\
\hline $\mathbf{4}$ & $\mathrm{REE}=1542.8 \mathrm{Ht}+23.4 \mathrm{VeMax}+7.5 \mathrm{Wt}-1629.1$ & 0.395 & 381.9 & 322.4 \\
\hline $\mathbf{5}$ & $\mathrm{REE}=1740.4 \mathrm{Ht}+50.2 \mathrm{PEEP}+34.6 \mathrm{Ve}-1876.1$ & 0.391 & 426.3 & 317.1
\end{tabular}

B

Late phase ( $\geq 6$ Days)

\begin{tabular}{|lllll|}
\hline Test set & Developed predictive equations & $\boldsymbol{R}^{\mathbf{2}}$ & RMSE & \multicolumn{1}{c}{ SEE } \\
\hline $\mathbf{1}$ & $\mathrm{REE}=919.1+12.0 \mathrm{Wt}+43.1 \mathrm{VeMax}-7.9 \mathrm{Age}$ & 0.491 & 328.5 \\
$\mathbf{2}$ & $\mathrm{REE}=1008.3+14.4 \mathrm{Wt}+26.1 \mathrm{VeMax}-7.9 \mathrm{Age}^{\mathrm{a}}$ & 0.498 & 423.6 & 335.9 \\
\hline $\mathbf{3}$ & $\mathrm{REE}=1143.3 \mathrm{Ht}+11.2 \mathrm{Wt}-8.9 \mathrm{Age}-318.4$ & 0.432 & 380.5 & 346.0 \\
\hline $\mathbf{4}$ & $\mathrm{REE}=1244.6 \mathrm{Ht}+10.6 \mathrm{Wt}-6.9 \mathrm{Age}-556.3$ & 0.398 & 301.7 & 364.5 \\
\hline $\mathbf{5}$ & $\mathrm{REE}=1445.3 \mathrm{Ht}+9.3 \mathrm{Wt}+27.6 \mathrm{VeMax}-1522.7$ & 0.363 & 395.3 & 344.4
\end{tabular}

Acute phase, $\leq 5$ days; $H R$ heart rate (beats/min); $\mathrm{Ht}$, Height $(\mathrm{m})$; late phase, $\geq 6$ days, PEEP positive end-expiratory pressure; $\mathrm{R}^{2}$, coefficient of determination, $R E E$ resting energy expenditure, RMSE root mean square error, SEE standard error of the estimate, TMax maximum body temperature in the previous $24 \mathrm{~h}\left({ }^{\circ} \mathrm{C}\right)$, VeMax maximum minute ventilation in the previous $24 \mathrm{~h}(\mathrm{~L} / \mathrm{min})$, Wt weight $(\mathrm{kg})$.

Multiple linear regression analysis was applied.

A stepwise method of variable selection applied. Model assumptions fulfilled.

No interactions between independent variables. No multicollinearity detected.

${ }^{\mathrm{a}}$ The selected equation.

Table 3. Comparison of REE calculated from predictive equations developed from same patients with measured REE during the acute ( $n=168)$ and late phases $(n=168)$.

\section{kcal/ day \\ Mean absolute \% difference}

\section{Underestimation}

Mean \% difference

Measured REE during the acute phase $=1747 \pm 429 \mathrm{kcal} /$ day

\begin{tabular}{|c|c|c|c|c|c|c|}
\hline $\begin{array}{l}\text { Predictive Equation } \\
\text { (Acute) }\end{array}$ & $\begin{array}{l}1751 \pm \\
275\end{array}$ & $15.2 \pm 13.8$ & $\begin{array}{l}-11.7 \pm 8.5 \text { (range: }-33.6 \text { to } \\
-0.04 ; n=82 \text { ) }\end{array}$ & $\begin{array}{l}43 / 168 \\
(25.6 \%)\end{array}$ & $\begin{array}{l}18.4 \pm 16.8 \text { (range: } 0.13 \text { to } \\
96.1 ; n=86 \text { ) }\end{array}$ & $\begin{array}{l}51 / 168 \\
(30.4 \%)\end{array}$ \\
\hline $\begin{array}{l}\text { Predictive } \\
\text { Equation (Late) }\end{array}$ & $\begin{array}{l}1887 \pm \\
302\end{array}$ & $18.6 \pm 17.7$ & $\begin{array}{l}-10.3 \pm 7.9 \text { (range: }-35.0 \text { to } \\
-0.61 ; n=55 \text { ) }\end{array}$ & $\begin{array}{l}26 / 168 \\
(15.5 \%)\end{array}$ & $\begin{array}{l}22.7 \pm 19.6 \text { (range: } 0.05 \text { to } \\
119.7 ; n=113 \text { ) }\end{array}$ & $\begin{array}{l}77 / 168 \\
(45.8 \%)\end{array}$ \\
\hline $\begin{array}{l}\text { Predictive Equation } \\
\text { (Acute) }\end{array}$ & $\begin{array}{l}1759 \pm \\
276\end{array}$ & $15.7 \pm 12.1$ & $\begin{array}{l}-14.2 \pm 9.2 \text { (range: }-36.9 \text { to } \\
-0.24 ; n=106 \text { ) }\end{array}$ & $\begin{array}{l}67 / 168 \\
(39.9 \%)\end{array}$ & $\begin{array}{l}18.3 \pm 15.6 \text { (range: } 0.29 \text { to } \\
61.7 ; n=62 \text { ) }\end{array}$ & $\begin{array}{l}38 / 168 \\
(22.6 \%)\end{array}$ \\
\hline $\begin{array}{l}\text { Predictive } \\
\text { Equation (Late) }\end{array}$ & $\begin{array}{l}1893 \pm \\
313\end{array}$ & $14.7 \pm 14.7$ & $\begin{array}{l}-10.4 \pm 8.8 \text { (range: }-41 \text { to } \\
-0.05 ; n=79)\end{array}$ & $\begin{array}{l}31 / 168 \\
(18.5 \%)\end{array}$ & $\begin{array}{l}18.6 \pm 17.6 \text { (range: } 0.27 \text { to } \\
77.3 ; n=89 \text { ) }\end{array}$ & $\begin{array}{l}55 / 168 \\
(32.7 \%)\end{array}$ \\
\hline
\end{tabular}

Acute phase $\leq 5$ days; late phase $\geq 6$ days; REE resting energy expenditure.

Predictive Equation (Acute): $1627.8 \mathrm{Ht}+25.3 \mathrm{VeMax}+8.4 \mathrm{Wt}-1830.3$.

Predictive Equation (Late): $1008.3+14.4 \mathrm{Wt}+26.1 \mathrm{VeMax}-7.9 \mathrm{Age}$.

both acute and late phases of critical illness in the Asian population.

Our previous study [14], which compared measured REEs using IC with predicted REEs from 15 commonly used PEs, showed that none of the REEs calculated using those PEs had very good accuracy and agreement at different phases of critical illness. Besides, we also found that patients in the acute phase had significantly lower mean REEs than patients in the late phase [14]. Considering the importance of these variations in energy requirements in different phases of critical illness, the recent ESPEN guidelines recommended a gradual increment of energy provision [2]. These provide us with the rationale to assess metabolic determinants of REE for the acute and late phases of critical illness.

In this study, the predicted REE calculated from two separate PEs developed from patients that had two IC measurements in acute and late phases had mean absolute percentage differences of $<20 \%$ when compared to measured REE in both phases, even though there appears to be a significant change in the severity of diseases between the two phases. In clinical practice, a 10-20\% difference between predicted and measured REE has been considered acceptable. Based on the current literature, a difference of $\pm 20 \%$ of energy intake does not produce any clinically meaningful difference in important outcomes [15, 25]. This 
Table 4. Tenfold cross-validation for predictive equations developed from all patients $(n=294)$.

\begin{tabular}{|c|c|c|c|c|}
\hline Test set & Developed predictive equations & $R^{2}$ & RMSE & SEE \\
\hline 1 & $\mathrm{REE}=1710.8 \mathrm{Ht}+7.3 \mathrm{Wt}+26.6 \mathrm{VeMax}-1906$ & 0.417 & 391.1 & 328.7 \\
\hline 3 & $\mathrm{REE}=2164.6 \mathrm{Ht}+19.6 \mathrm{BMI}+39.4 \mathrm{Ve}-2651$ & 0.397 & 325.3 & 338.8 \\
\hline 5 & $\mathrm{REE}=1492.1 \mathrm{Ht}+7.7 \mathrm{Wt}+40.9 \mathrm{Ve}-1582$ & 0.399 & 276.9 & 343.0 \\
\hline 6 & $\mathrm{REE}=1785.9 \mathrm{Ht}+7.4 \mathrm{Wt}+31.0 \mathrm{VeMax}-2087$ & 0.426 & 349.0 & 334.3 \\
\hline 7 & $\mathrm{REE}=1774.0 \mathrm{Ht}+7.2 \mathrm{Wt}+32.0 \mathrm{VeMax}-2049$ & 0.424 & 403.3 & 328.1 \\
\hline 9 & $\mathrm{REE}=1564.2 \mathrm{Ht}+7.9 \mathrm{Wt}+28.7 \mathrm{VeMax}-1727$ & 0.396 & 338.1 & 335.3 \\
\hline 10 & $\mathrm{REE}=1691.6 \mathrm{Ht}+7.8 \mathrm{Wt}+23.3 \mathrm{VeMax}-1878$ & 0.390 & 397.9 & 328.0 \\
\hline
\end{tabular}

$B M I$ body mass index $\left(\mathrm{kg} / \mathrm{m}^{2}\right), H t$ height $(\mathrm{m}), R^{2}$ coefficient of determination, REE resting energy expenditure, RMSE root mean square error, SEE standard error of the estimate, TMax maximum body temperature in the previous $24 \mathrm{~h}\left({ }^{\circ} \mathrm{C}\right)$, VeMax maximum minute ventilation in the previous $24 \mathrm{~h}(\mathrm{~L} / \mathrm{min}), \mathrm{Ve}$ Minute Ventilation (L/min), Wt weight $(\mathrm{kg})$.

Multiple linear regression analysis was applied.

A stepwise method of variable selection applied. Model assumptions fulfilled.

No interactions between independent variables. No multicollinearity detected.

${ }^{\text {a }}$ The selected equation.

Table 5. Comparison of REE calculated from predictive equation developed from all patients with measured REE during the acute $(n=294)$ and late phases $(n=180)$.

\section{kcal/ day \\ Mean absolute \% difference}

Underestimation

Mean \% difference

Measured REE during the acute phase $=1757 \pm 431 \mathrm{kcal} /$ day

$\begin{array}{llll}\text { Predictive } & 1773 \pm & 15.1 \pm 14.2 & -12.1 \pm 8.4 \\ \text { Equation } & 284 & & n=130)\end{array}$

Measured REE during the late phase $=1886 \pm 508 \mathrm{kcal} / \mathrm{day}$

$\begin{array}{llll}\text { Predictive } & 1807 \pm & 15.0 \pm 13.1 & -13.5 \pm 8.6 \text { (range: }-39.2 \text { to }-0.04 ; \\ \text { Equation } & 315 & & n=103 \text { ) }\end{array}$

Equation 315

$n=103)$

\section{Overestimation}

Mean \% difference

$>+10 \%$
(33.3\%)

$17.6 \pm 17.1$ (range: 0.1 to 113 ; $n=164)$

$69 / 294$

$(23.5 \%)$

$17.0 \pm 17.2$ (range: 0.06 to $79.4 ; 40 / 180$ $n=77$ )
328.7

25.6

338.8

343.0

34.3

328.1

34.0 .

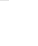

Acute phase, $\leq 5$ days; late phase, $\geq 6$ days; $R E E$, resting energy expenditure

Predictive Equation (all patients in the acute phase, $n=294$ ) $: 891.6 \mathrm{Ht}+9.0 \mathrm{Wt}+39.7 \mathrm{Ve}-5.6 \mathrm{Age}-354$.

diminished the clinical reasoning for needing two separate equations for the different phases. A larger difference of measured REE between the acute and late phases may become more evident with a larger sample size and time-lapse. From these results, we decided to develop and validate a single PE among all patients with REE measured in the acute phase only, given the larger sample size. This single PE developed from the acute phase has been found to be optimal for estimating REE in both the acute and late phases.

Studies have shown that REE is influenced by many factors, including age, sex, body composition, body temperature, body movement, environmental temperature, heart rate, and disease status [26-28]. Pharmacological agents, such as analgesics, sedatives, and muscle relaxant reduce REE, while vasopressors increase REE [29]. REE can fluctuate throughout illness and can increase due to stress-induced metabolic effects in critically ill patients [30]. In this study, height, weight, minute ventilation and age were the main determinants of REE, and they explained about $44.2 \%$ of the variations in REE. The explanatory power of our variables is comparable with those reported in other studies that had developed PEs for ICU populations, such as Penn State [31], Raurich [32], Brandi [33], Faisy [13] and Swinamer [12], where the reported explanatory power ranges from $37 \%$ to $77 \%$. The moderate performance of PEs developed for critically ill patients is expected as many factors will influence REE [26-30] and a PE estimates REE from only a few variables that are highly correlated with measured REE.

In the present study, weight and age were the 'static' variables selected for use in the prediction models of both the acute and late phases. Older patients may have lower REEs partly because of age-associated changes in body composition and the relative size of fat-free mass (FFM) components [27, 34, 35]. Many studies have shown that body weight and FFM (the metabolizing mass of the body) correlate with REE [35-37]. However, the relationship between REE and body weight is nonlinear at the extremes of body weight $[22,27,38]$. A disturbance in the ratio of total body weight, organ, and muscle can distort the association between body weight and REE, especially among underweight, obese and muscular individuals $[34,36]$. For these reasons, patients with BMI $<15 \mathrm{~kg} / \mathrm{m}^{2}$ and $\mathrm{BMI}>40 \mathrm{~kg} / \mathrm{m}^{2}$ were excluded from this analysis.

In this study, multivariate analysis showed that the independent variables defining REE were those related to metabolism (age, weight, height, and minute ventilation). Of note, one "dynamic" variable which is minute ventilation was selected in the final prediction model. Minute ventilation, which is determined by the respiratory rate and tidal volume, depends on the sedation level or the ventilator setting. During the acute phase, patients are unstable, and the dynamic nature of minute ventilation may be able to better reflect the metabolic rate of the patients in this phase. Minute ventilation has also been included in previous equations for estimating the REE of critically ill patients [9, 13, 33]. Minute ventilation maintains acid-base homoeostasis and stable carbon dioxide status in an individual. The relationship between minute ventilation and REE is predicted because carbon dioxide production $\left(\mathrm{VCO}_{2}\right)$ is a part of the Weir equation $(27,28)$. Furthermore, the increase in REE with an increase of $\mathrm{VCO}_{2}$ is the main cause for increased minute ventilation requirements in long- 
staying mechanically ventilated patients [39]. Compared with PEs that use only 'static' variables, it is preferable to include dynamic variables in the PEs because PEs with "dynamic" variables are more consistent with REEs measured by IC [14].

The present study used predicted body cell mass (BCM) to explore the relationship between measured REE and body composition. This was a significant but weak correlation $(r=0.234$ in the acute phase, $r=0.257$ in late phase; $p<0.05$ ) and thus was not selected for use in either of the prediction models. The probable reasons were that body composition values are influenced by stress conditions, injury and abnormal fluid status in critical illness [40, 41], and the predictive equation for calculating BCM [42] used in our study may be less accurate. The variable 'energy intake in the previous $24 \mathrm{~h}$ ' was also not selected for use in the prediction model in the late phase even though statistically it is correlated with REE. This is because the problem of multicollinearity might exist as energy intake was guided by measured REE since early phase and use of this variable will lead to large variations of calculated REE as the variations in energy intake of patients can range from $0 \mathrm{kcal} / \mathrm{day}$ when nil by mouth to about $2000 \mathrm{kcal} /$ day when given full feeding. Furthermore, the effect of DIT on REE is less than $5 \%$ when patients are not overfed and are on continuous nutrition support [43-45]. IC measurements in our study were performed without discontinuing nutrition support and patients were not overfed (mean energy adequacy $87.1 \pm 20.2 \%$ ). The current study also did not include body temperature in the new predictive model because most of the patients were in normothermia condition (mean $36.71 \pm 0.86^{\circ} \mathrm{C}$ ) during IC measurements, although variations of 5\% REE per degree Celsius has been found in other ICU studies [13, 32].

Recently, ventilator-derived $\mathrm{VCO}_{2}$ has been proposed for estimating REE as it was shown to be more accurate than PEs $[46,47]$. However, further validation showed that it has a low agreement with IC-measured REE [48]. Experts have also suggested that this simplistic approach cannot reflect the complex physiological changes that critically ill patients undergo [49]. Besides, this method needs a special ventilator that can measure $\mathrm{VCO}_{2}$. Thus, PEs are still routinely used in daily practice and in critical care nutrition trials when IC is not feasible $[15,24]$.

This study has several limitations. First, the PEs generated in this single-centre study has limited generalizability. Second, as the measured or estimated body weight may not reflect actual weight (due to acute fluid shifts), this could have introduced errors in the prediction model. Third, despite efforts to ensure that every measurement was done in a standardized manner, the accuracy of IC measurements was inevitably influenced by metabolic factors, such as changes in body composition, medications, disease status, changes of ventilator mode, nutrients absorption and body temperature.

On the other hand, this study also has several strengths. First, the PE for critically ill Asian patients were developed and validated by considering the variable, dynamic, and complex nature of metabolic changes at different phases of critical illness. Second, this is a prospective study with a relatively large sample size and large number of variables in both the acute and late phases. Third, the use of multi-fold cross-validation is considered a robust internal-external validation method for the PEs, which can accurately predict out-of-sample accuracy and use data more efficiently as all observations are used for both testing and training $[20,21]$. Fourth, the use of a single carefully calibrated device and the application of the standardized method for measuring REE minimized variations in the measurements. Lastly, a Microsoft Excel Tah et al. equation calculator (Supplementary File), which is a practical and simple-to-use tool is provided to facilitate the use of the developed PE in the ICU setting.

\section{CONCLUSIONS}

Two separate predictive equations for estimating REE in the acute ( $\leq 5$ days) and late ( $\geq 6$ days) phases of critical illness may not be necessary. An equation was developed and internally validated among patients with IC measurement in the acute phase. The equation is [891.6 (Height in $\mathrm{m}$ ) +9.0 (Weight in $\mathrm{kg}$ ) +39.7 (Minute Ventilation in L/min) - 5.6 (Age) - 354](Tah et al. equation). Comparison of the REE estimated from this new predictive equation with measured REE has demonstrated that it can provide optimal estimates of REE for patients in both acute and late phases. Thus, when IC measurement is not possible, this PE may be useful, especially for Asian critically ill patients. Future studies are needed to validate this newly developed PE externally.

\section{DATA AVAILABILITY}

The data sets generated and/or analysed during the current study are not publicly available due to the data confidentiality requirements of the ethics committee but are available from the corresponding author on reasonable request and approval from the ethics committee.

\section{REFERENCES}

1. McClave SA, Taylor BE, Martindale RG, Warren MM, Johnson DR, Braunschweig C, et al. Guidelines for the Provision and Assessment of Nutrition Support Therapy in the Adult Critically III Patient: Society of Critical Care Medicine (SCCM) and American Society for Parenteral and Enteral Nutrition (A.S.P.E.N.). J Parenter Enter Nutr. 2016;40:159-211.

2. Singer P, Blaser AR, Berger MM, Alhazzani W, Calder PC, Hiesmayr M, et al. ESPEN guideline on clinical nutrition in the intensive care unit. Clin Nutr. 2019;38:48-79.

3. Singer $P$, Anbar R, Cohen J, Shapiro H, Shalita-Chesner M, Lev S, et al. The tight calorie control study (TICACOS): a prospective, randomized, controlled pilot study of nutritional support in critically ill patients. Intensive Care Med. 2011;37:601-9.

4. Zusman O, Theilla M, Cohen J, Kagan I, Bendavid I, Singer P. Resting energy expenditure, calorie and protein consumption in critically ill patients: a retrospective cohort study. Crit Care. 2016;20:1-8.

5. Singer P, De Waele E, Sanchez C, Ruiz Santana S, Montejo JC, Laterre PF, et al. TICACOS international: a multi-center, randomized, prospective controlled study comparing tight calorie control versus Liberal calorie administration study. Clin Nutr. 2021 40:380-7.

6. Heyland DK, Cahill N, Day AG. Optimal amount of calories for critically ill patients: depends on how you slice the cake! Crit Care Med. 2011;39:2619-26.

7. Singer $P$, Singer J. Clinical guide for the use of metabolic carts: indirect calorimetry-No longer the orphan of energy estimation. Nutr Clin Pr. 2016;31:30-8.

8. Rattanachaiwong $S$, Singer P Should we calculate or measure energy expenditure? Practical aspects in the ICU. Vols. 55-56, Nutrition. Elsevier Inc.; 2018. p. 71-5.

9. Frankenfield D, Coleman A, Alam S, Cooney RN. Analysis of estimation methods for resting metabolic rate in critically ill adults. J Parenter Enter Nutr. 2009;33:27-36.

10. Harris JA, Benedict FG A biometric study of human basal metabolism Washington, DC Carnegie Inst Washingt 1919;370-3.

11. Mifflin $D$, Jeor $T, A H L$, Scott BJ, Daughertky SA, Koh YO. A new predictive equation for resting energy expenditure in healthy individuals. Am J Clin Nutr. 1990;51:241-7.

12. Swinamer DL, Grace MG, Hamilton SM, Jones RL, King EG, Roberts P. Predictive equation for assessing energy expenditure in mechanically ventilated critically ill patients. Crit Care Med. 1990;18:657-61.

13. Faisy C, Guerot E, Diehl JL, Labrousse J, Fagon JY. Assessment of resting energy expenditure in mechanically ventilated patients. Am J Clin Nutr. 2003;78:241-9.

14. Tah PC, Lee Z-Y, Poh BK, Abdul Majid H, Hakumat-Rai V-R, Mat Nor MB, et al. A single-center prospective observational study comparing resting energy expenditure in different phases of critical illness: indirect calorimetry versus predictive equations. Crit Care Med. 2020;48:e380-90.

15. Arabi YM, Aldawood AS, Haddad SH, Al-Dorzi HM, Tamim HM, Jones G, et al. Permissive underfeeding or standard enteral feeding in critically ill adults. $\mathrm{N}$ Engl J Med. 2015;372:2398-408.

16. Frankenfield D, Ashcraft CM, Galvan DA. Prediction of resting metabolic rate in critically ill patients at the extremes of body mass index. J Parenter Enter Nutr. 2013;37:361-7.

17. Knofczynski GT, Mundfrom D. Sample sizes when using multiple linear regression for prediction. Educ Psychol Meas. 2008;68:431-42.

18. Walter SD, Eliasziw M, Donner A. Sample size and optimal designs for reliability studies. Stat Med. 1998;17:101-10.

19. Oshima T, Berger MM, De Waele E, Guttormsen AB, Heidegger C-P, Hiesmayr M, et al. Indirect calorimetry in nutritional therapy. A position paper by the ICALIC study group. Clin Nutr. 2017 36:651-62. 
20. Ejlerskov KT, Jensen SM, Christensen LB, Ritz C, Michaelsen KF, Mølgaard C. Prediction of fat-free body mass from bioelectrical impedance and anthropometry among 3-year-old children using DXA. Sci Rep. 2015;4:3889. May 27

21. Hastie T, Tibshirani R, Friedman J. The elements of statistical learning. Springe Ser Stat. 2009;27:764.

22. Frankenfield D, Roth-Yousey L, Compher C. Comparison of predictive equations for resting metabolic rate in healthy nonobese and obese adults: a systematic review. J Am Diet Assoc. 2005;105:775-89.

23. Tatucu-Babet OA, Ridley EJ, Tierney AC. Prevalence of underprescription or overprescription of energy needs in critically ill mechanically ventilated adults as determined by indirect calorimetry: a systematic literature review. J Parenter Enter Nutr. 2016;40:212-25.

24. National Heart, Lung, and Blood Institute Acute Respiratory Distress Syndrome (ARDS) Clinical Trials Network, Rice TW, Wheeler AP, et al. Initial trophic vs full enteral feeding in patients with acute lung injury: the EDEN randomized trial. JAMA. 2012;307:795-803.

25. Chapple L anne S, Weinel L, Ridley EJ, Jones D, Chapman MJ, Peake SL. Clinical sequelae from overfeeding in enterally fed critically III adults: where is the evidence? J Parenter Enter Nutr. 2019;00.

26. Frankenfield D, Ashcraft CM. Estimating energy needs in nutrition support patients. J Parenter Enter Nutr. 2011;35:563-70. Sep 10

27. Frankenfield $D$. Factors related to the assessment of resting metabolic rate in critically III patients. J Parenter Enter Nutr. 2019;43:234-44. Feb 21

28. Mtaweh H, Jose M, Aguero S, Campbell M, Allard JP, Pencharz P, et al. Systematic review of factors associated with energy expenditure in the critically ill. Clin Nutr ESPEN. 2019;33:111-24.

29. Schulman RC, Mechanick Jl. Metabolic and nutrition support in the chronic critical illness syndrome. Respir Care. 2012;57:958-77.

30. Psota T, Chen KY. Measuring energy expenditure in clinical populations: rewards and challenges. Eur J Clin Nutr. 2013;67:436-42.

31. Frankenfield D, Smith JS, Cooney RN. Validation of 2 approaches to predicting resting metabolic rate in critically ill patients. J Parenter Enter Nutr. 2004;28:259-64.

32. Raurich JM, Llompart-Pou JA, Ferreruela M, Riera M, Homar J, Marse $P$, et al. A simplified equation for total energy expenditure in mechanically ventilated critically ill patients. Nutr Hosp. 2015;32:1273-80.

33. Brandi LS, Santini L, Bertolini R, Malacarne P, Casagli S, Baraglia AM. Energy expenditure and severity of injury and illness indices in multiple trauma patients. Crit Care Med. 1999;27:2684-9.

34. Javed F, He Q, Davidson LE, Thornton JC, Albu J, Boxt L, et al. Brain and high metabolic rate organ mass: Contributions to resting energy expenditure beyond fat-free mass. Am J Clin Nutr. 2010;91:907-12.

35. Hölzel C, Weidhase L, Petros $S$. The effect of age and body mass index on energy expenditure of critically ill medical patients. Eur J Clin Nutr. 2021;75:464-72. Mar 16

36. Müller MJ, Bosy-Westphal A, Kutzner D, Heller M. Metabolically active components of fat-free mass and resting energy expenditure in humans: recent lessons from imaging technologies. Obes Rev. 2002;3:113-22.

37. Purcell SA, Elliott SA, Walter PJ, Preston T, Cai H, Skipworth RJE, et al. Total energy expenditure in patients with colorectal cancer: associations with body composition, physical activity, and energy recommendations. Am J Clin Nutr. 2019;110:367-76.

38. Livingston $\mathrm{EH}$, Kohlstadt I. Simplified resting metabolic rate-predicting formulas for normal-sized and obese individuals. Obes Res. 2005;13:1255-62.

39. Kiiski R, Takala J. Hypermetabolism and efficiency of $\mathrm{CO}_{2}$ removal in acute respiratory failure. Chest. 1994;105:1198-203.

40. Ismael S, Savalle M, Trivin C, Gillaizeau F, D'Auzac C, Faisy C. The consequences of sudden fluid shifts on body composition in critically ill patients. Crit Care. 2014;18:1-10.

41. Soares MJ, Müller MJ. Resting energy expenditure and body composition: critical aspects for clinical nutrition. Eur J Clin Nutr. 2018;72:1208-14. Sep 5

42. Savalle M, Gillaizeau F, Maruani G, Puymirat E, Bellenfant F, Houillier P, et al. Assessment of body cell mass at bedside in critically ill patients. Am J Physiol Metab. 2012;303:E389-96.

43. Raurich $\mathrm{JM}$, Ibanez $\mathrm{J}$, Marse $\mathrm{P} . \mathrm{CO}_{2}$ production and thermogenesis induced by enteral and parenteral nutrition. Nutr Hosp. 1996;11:108-13.

44. Heymsfield SB, Casper K. Continuous nasoenteric feeding: bioenergetic and metabolic response during recovery from semistarvation. Am J Clin Nutr. 1988;47:900-10.

45. Frankenfield D. Impact of feeding on resting metabolic rate and gas exchange in critically III patients. J Parenter Enter Nutr. 2019;43:226-33.

46. Stapel SN, de Grooth HJS, Alimohamad H, Elbers PWG, Girbes ARJ, Weijs PJM, et al. Ventilator-derived carbon dioxide production to assess energy expenditure in critically ill patients: Proof of concept. Crit Care. 2015;19.
47. Rousing ML, Hahn-Pedersen MH, Andreassen S, Pielmeier U, Preiser JC. Energy expenditure in critically ill patients estimated by population-based equations, indirect calorimetry and CO2-based indirect calorimetry. Ann Intensive Care. 2016;6:1-11.

48. Kagan I, Zusman O, Bendavid I, Theilla M, Cohen J, Singer P Validation of carbon dioxide production (VCO2) as a tool to calculate resting energy expenditure (REE) in mechanically ventilated critically ill patients: a retrospective observational study. Crit Care. 2018.

49. Singer P. Simple equations for complex physiology: can we use $\mathrm{VCO}_{2}$ for calculating energy expenditure? Crit Care. 2016;20:72.

\section{ACKNOWLEDGEMENTS}

Funding Support: Ministry of Education Malaysia, Fundamental Research Grant Scheme (FRGS) [grant number FRGS/1/2018/SKK02/UM/02/3 with project code FP003-2018A]; Educational grant from the Parenteral and Enteral Nutrition Society of Malaysia (PENSMA). We are grateful to the subjects and their families for their participation in this project. We wish to thank all the personnel from the Intensive Care Unit, University of Malaya Medical Centre, Department of Anaesthesiology, University of Malaya, and Department of Dietetics, University of Malaya Medical Centre for their contributions and support of this project.

\section{AUTHOR CONTRIBUTIONS}

$P C T, B K P, C C K, Z Y L, V R H R, M B M N, M K Z, H A M$ and MSH contributed to the conceptualization and design of the study; $\mathrm{PCT}$ recruited the patients and collected the data; PCT, CCK and ZYL contributed to the acquisition and analysis of data; PCT, $\mathrm{BKP}, \mathrm{CCK}, \mathrm{ZYL}, \mathrm{HAM}$ and MSH contributed to the interpretation of data; PCT drafted the manuscript; $P C T$ and MSH contributed to the funding acquisition. All authors agree to be fully accountable for ensuring the integrity and accuracy of the work. All authors have read and agreed to the published version of the manuscript.

\section{FUNDING INFORMATION}

The study was funded by the Ministry of Education Malaysia, Fundamental Research Grant Scheme (FRGS) [grant number FRGS/1/2018/SKK02/UM/02/3 with project code FP003-2018A] awarded to Associate Professor Dr M. Shahnaz Hasan. Ms Tah Pei Chien received educational grant from the Parenteral and Enteral Nutrition Society of Malaysia (PENSMA). All other co-authors have no financial disclosures. The sponsor of the study had no role in the design of the study and collection, analysis, and interpretation of data and in writing the manuscript

\section{COMPETING INTERESTS}

The authors declare no competing interests.

\section{ETHICS APPROVAL AND CONSENT TO PARTICIPATE}

Ethics approval was granted by the Medical Research Ethics Committee (MREC), UMMC (MREC ID NO: 20161024-4407) and registered with the National Medical Research Register (NMRR) Malaysia (NMRR.ID: NMRR-16-2030-33143) and ClinicalTrials.gov (NCT03319329). Informed consent was obtained from the patients or their legal representative.

\section{ADDITIONAL INFORMATION}

Supplementary information The online version contains supplementary material available at https://doi.org/10.1038/s41430-021-00999-y.

Correspondence and requests for materials should be addressed to M. Shahnaz Hasan.

Reprints and permission information is available at http://www.nature.com/ reprints

Publisher's note Springer Nature remains neutral with regard to jurisdictional claims in published maps and institutional affiliations. 